\title{
Prevalence and Factors Influencing Use of Herbal Medicines During Pregnancy in Hail, Saudi Arabia A cross-sectional study
}

"Mohamad Aljofan ${ }^{1}$ and Suhaib Alkhamaiseh ${ }^{2,3}$

$$
\begin{aligned}
& \text { معدل الانتشار والعوامل المؤثرة في استخدام الأدوية العشبية أثناء } \\
& \text { الحمل في حائل بالمملكة العربية السعودية } \\
& \text { دراسة مستعرضة }
\end{aligned}
$$

$$
\text { محمد الجوفان و صهيب الخمايسة }
$$

\begin{abstract}
Objectives: The increasing prevalence of herbal medicine use is a global public health concern. Critically, many women continue to use herbal medicines during pregnancy despite potential maternofetal risks. The current study aimed to determine the prevalence of and factors associated with herbal medicine use during pregnancy in Saudi Arabia. Methods: This cross-sectional study was conducted between February and May 2017. An Arabic-language 33item survey assessing herbal medicine use was designed and distributed to 879 random women attending outpatient clinics at governmental and private hospitals in Hail, Saudi Arabia. Only women who were pregnant or had been pregnant in the previous 10 years were included. Results: The mean age of the participants was 29.5 years, with $49 \%$ under 30 years old. Overall, 33\% of the respondents claimed to have used herbal medicines during pregnancy. The most common reasons for doing so were to improve lactation (73\%), improve the course of the pregnancy (56\%) and facilitate labour (49\%). Women who worked full-time and those with high school diplomas or above were significantly more likely to use herbal medicines during pregnancy $(P<0.001$ each). Conclusion: To the best of the authors' knowledge, this is the first study to determine the prevalence and associated factors of herbal medicine use during pregnancy in Hail. The results showed a high prevalence of herbal medicine use among pregnant women in the region. Healthcare providers should therefore ensure that patients disclose the use of herbal medicines during pregnancy to avoid treatment complications or adverse herb-drug interactions.
\end{abstract}

Keywords: Herbal Medicine; Plant Preparations; Pregnancy; Complementary Therapies; Health Behaviors; Prevalence; Herb-Drug Interactions; Saudi Arabia.

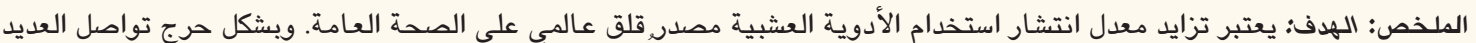

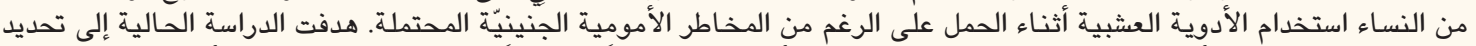

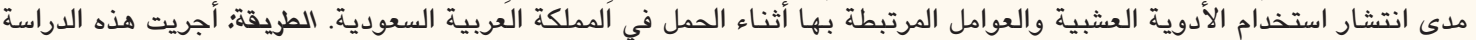

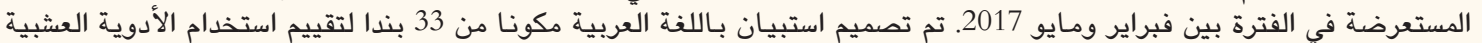

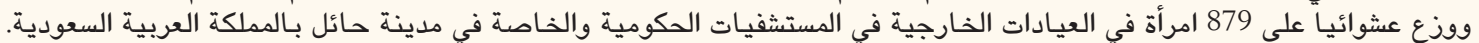

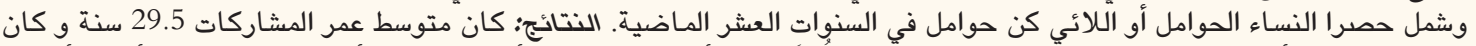

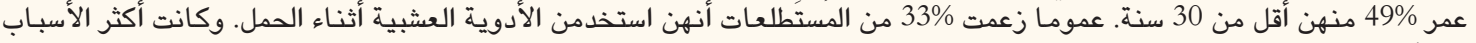

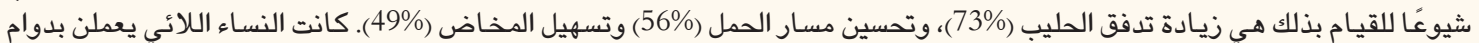

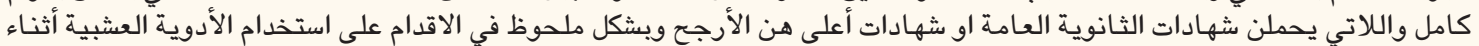

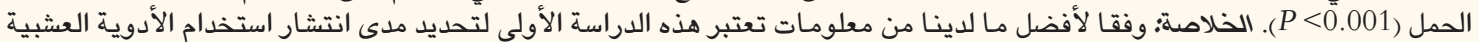

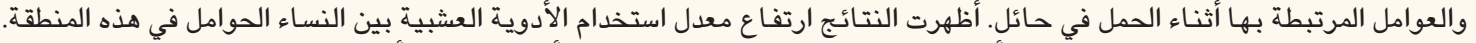

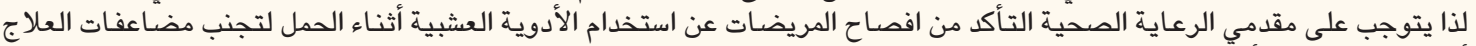
أو التفاعلات بين الأدوية العشبية والعابة العقاقير.

الكلمات المفتاحية؛ دواء عُشبي؛ مستحضرات نباتية؛ حمل؛ علاجات تكميلية؛ سلوكيات صحية؛ معدل انتشار؛ تفاعلات الأدوية العشبية والعقاقير؛ المملكة العربية السعودية.

\footnotetext{
AdVANCES IN KNOWLEDGE

To the best of the authors' knowledge, this is the first study to determine the prevalence of herbal medicine use during pregnancy in Hail, Saudi Arabia.

The findings of this study may improve understanding of factors which influence the use of herbal medicines during pregnancy, particularly those related to local cultural beliefs, such as the belief in the safety and efficacy of herbal medicine.
} 
The results of the current study provide insight into the specific characteristics of herbal medicine users in Hail.

Herbal medicine users are likely to have at least 12 years of education and be working full-time.

\section{Application to Patient Care}

Healthcare providers should encourage pregnant patients to disclose any herbal medicine use and ensure that such individuals are aware of potential interactions with prescription and over-the-counter drugs prior to the initiation of treatment.

$\mathrm{H}$ ERBAL MEDiCINE USE REFERS TO THE USE of plant-derived materials or preparations to treat, diagnose and prevent illnesses and maintain well-being. ${ }^{1}$ The use of herbal medicine is a common practice in different parts of the world, particularly in developing countries, despite limited scientific evidence establishing the safety and efficacy of such products. ${ }^{2,3}$ According to the World Health Organization, an estimated $40 \%$ of all healthcare services in China comprise traditional medicines and up to $80 \%$ of Africans still use traditional medicine to meet their healthcare needs. ${ }^{4}$ Such treatments are also rapidly gaining momentum in more developed countries where they are referred to under the umbrella term of complementary alternative medicine (CAM). ${ }^{5-9}$

According to Eisenberg et al., approximately onethird of American adults in a national sample reported using at least one unconventional therapy in the past year. ${ }^{5}$ In Australia, MacLennan et al. reported that $48.5 \%$ of individuals used at least one non-medicallyprescribed alternative medicine, excluding calcium, iron and prescribed vitamins. ${ }^{7}$ Moreover, results from the 2007 National Health Interview Survey indicated that approximately $38 \%$ of adults and $12 \%$ of children in the USA were using CAM in some form that year. ${ }^{8}$ Another study in the USA estimated that one in five American adults take herbal products. ${ }^{9}$

The unregulated use of herbal medicines during pregnancy presents a high risk for pregnant women and the developing fetus. ${ }^{10}$ Alarmingly, despite the lack of scientific evidence to support its use, there is an increasing trend in the prevalence of herbal medicine use during pregnancy. ${ }^{11}$ Kim Sooi and Lean Keng found that $34 \%$ of pregnant Malaysian women used herbal medicines during their pregnancy. ${ }^{12}$ In the USA, an estimated 6-9\% of pregnant women use herbal medicines, with this statistic increasing to an alarming 69\% in Russia. ${ }^{13,14}$

Like many countries in the region, the use of herbal medicine in Saudi Arabia is high; a recent study reported that $94 \%$ of 1,300 respondents from northern regions of the country had a history of herbal product use. ${ }^{15}$ However, to the best of the authors' knowledge, no previous study has assessed the use of herbal medicines among pregnant women in the Hail region of northern Saudi Arabia. The current study therefore aimed to determine the prevalence of and factors influencing the use of herbal medicines during pregnancy in Hail. As the prevalence of herbal medicine use is fairly high in this region, it was hypothesised that there would be a similarly high frequency of herbal product use during pregnancy, particularly in the early stages to alleviate symptoms of nausea and vomiting.

\section{Methods}

This cross-sectional questionnaire-based study was carried out between February and May 2017 at various governmental and private hospitals in Hail. A convenience sampling methodology was used to randomly recruit women from the outpatient clinics of Hail Maternal Hospital, General Hail Hospital and Salamat Private Hospital, as well as other participating health centres. Only adult women, $\geq 18$ years of age, who were currently or had previously been pregnant in the last 10 years were included in the study. Those who were mentally handicapped were excluded from the study.

In order to determine the prevalence of herbal medicine use among the pregnant population in the region, the minimum sample size needed was calculated according to the following equation: ${ }^{15}$

$$
n=\frac{Z^{2} \times P \times(1-P)}{d^{2}} \quad[\text { Equation } 1]
$$

where $Z$ is the $Z$ statistic (2.576) at a $99 \%$ confidence interval (CI), $P$ is the standard deviation $(0.5)$ and $d$ is the margin of error (0.05). This resulted in a value of 663.57 , which was rounded up to 664 individuals at a $99 \%$ CI with a margin of error of $1 \%$ [Equation 1]. However, in order to ensure that the sample was truly representative, a total of 879 women were recruited to participate in the study.

An English-language questionnaire was developed to assess the prevalence of herbal medicine use during pregnancy, reasons for use and knowledge regarding potential health risks. The questionnaire contained 33 items divided into four different sections, including a section to assess the participants' demographic characteristics as well as knowledge, attitudes and practices regarding herbal medicine use during pregnancy. Subsequently, the questionnaire was translated into Arabic by proficient Arabic-language speakers and revised to be suitable for use in the general population. 
A pilot study of 21 randomly selected women was performed to validate the questionnaire. The participants included 14 pregnant women attending the Outpatient Department of the Hail Maternal Hospital, five employees from the same institution and two participants from the University of Hail. After corrections were made based on feedback from the pilot study, the final questionnaire was distributed to the participants by research assistants who met the participants at the outpatient departments of each of the participating hospitals.

Data were recorded using a data collection form and entered into an Excel spreadsheet, Version 2010 (Microsoft Corp., Redmond, Washington, USA). Statistical analysis was conducted using the Statistical Package for the Social Sciences (SPSS), Version 21.0 (IBM Corp., Armonk, New York, USA). A Chi-squared test was used to test associations between variables. An a priori level of $P<0.010$ was considered statistically significant.

This study received ethical approval from the Scientific Research Ethical Committee of the University of Hail (H-2017-015). All procedures were performed in accordance with the revised Declaration of Helsinki. Informed consent was obtained from all participants subsequent to the provision of full details regarding the study and its intended purpose. In addition, all of the women were made aware that their participation was voluntary and that no identifying information would be collected. During the study period, the data collection forms were kept in a secure environment, accessible only to the principal investigator and were destroyed following completion of the study.

\section{Results}

The mean age of the study participants was 29.5 years, with $49 \%$ under the age of 30 years old. In terms of education level, the vast majority (96\%) had a high school diploma or above. Approximately half of the respondents (49\%) were working full-time, while the remainder were housewives. At the time of the survey, 623 (71\%) participants were pregnant and 256 (29\%) were not currently pregnant but had had full-term pregnancies in the past 10 years. Most of the participants (62\%) lived in urban areas, while the remaining participants (38\%) lived in rural areas outside of Hail City [Table 1].

Overall, 712 women (81\%) reported that they had used herbal medicine regularly before their pregnancies. In addition, 294 women (33\%) admitted to using such products during pregnancy [Figure 1]. Among the 294 respondents who had used herbal medicines while pregnant, 59 (20\%) had used herbal products
Table 1: Demographic characteristics of women attending outpatient clinics in Hail, Saudi Arabia $(\mathrm{N}=879)$

\begin{tabular}{lc} 
Variable & $\mathbf{n}(\%)$ \\
Age in years & \\
$18-29$ & $432(49)$ \\
$30-39$ & $291(33)$ \\
$40-49$ & $135(15)$ \\
$\geq 50$ & $21(2)$ \\
Mean \pm SD (range) & $29.5 \pm 6.6(18-53)$ \\
Education level & \\
None* & $39(4)$ \\
High school diploma & $461(52)$ \\
College & $379(43)$ \\
Place of residence & \\
Urban & $544(62)$ \\
Rural & $335(38)$ \\
Pregnancy status & \\
Currently pregnant & $623(71)$ \\
Previously pregnant & $256(29)$ \\
Employment status & \\
Housewife & $428(49)$ \\
Working full-time & \\
\hline
\end{tabular}

"Less than 12 years of formal study.

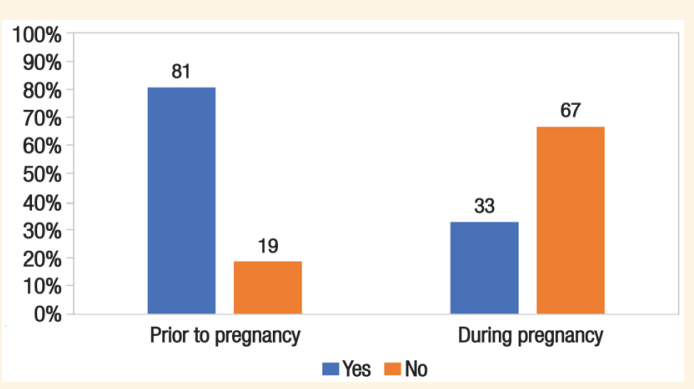

Figure 1: Prevalence of herbal medicine use before and during pregnancy among women attending outpatient clinics in Hail, Saudi Arabia (N = 879).

during the first trimester, 132 (45\%) during the second trimester and 103 (35\%) during the third trimester. Among the 256 women who were not currently pregnant at the time of the survey, 217 (85\%) admitted to using herbal medicines during the lactation period $(P<0.001)$ [Figure 2].

The most commonly reported reasons for using herbal medicines during pregnancy were to increase milk supply during the lactation period (73\%), to improve the course of the pregnancy (56\%) and to facilitate labour (49\%) [Figure 3]. In terms of their 


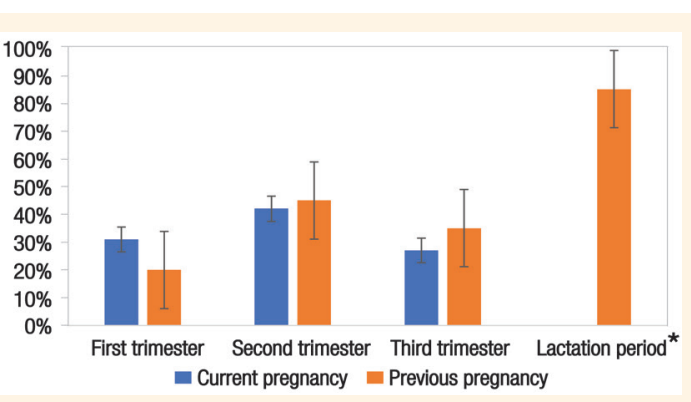

Figure 2: Patterns of herbal medicine use during pregnancy among women attending outpatient clinics in Hail, Saudi Arabia $(\mathrm{n}=294)$.

"Significant at $P<0.010$

knowledge of health risks, most respondents (74\%) believed that the moderate consumption of herbal medicines would affect neither the mother nor the fetus. However, the women believed that excessive use would lead to negative outcomes such as miscarriage (41\%), premature labour (33\%), birth defects (12\%), long-term maternal health effects $(9 \%)$ and stillbirth (5\%) [Table 2].

After adjusting for potential confounders, a multivariable linear regression model was used to identify factors influencing herbal medicine use during pregnancy. Women with a high school diploma or above ( $\beta=0.361,95 \%$ CI: $0.230-0.344 ; P<0.001)$ and those working full-time ( $\beta=0.271,95 \% \mathrm{CI}$ : $0.485-0.592$; $P<0.001)$ were significantly more likely to use herbal medicines during pregnancy [Table 3].

\section{Discussion}

In many developed countries, herbal medicines are strictly regulated by legislation to ensure the quality, safety and efficacy of these therapeutic products., ${ }^{3,16,17}$ In contrast, herbal medicines in developing countries such as Saudi Arabia are usually unregulated and formulated without rigorous scientific testing or physician consultation. This increases the risk of abnormal pathologies or toxicities, especially among vulnerable

Table 2: Beliefs regarding the risks of excessive herbal medicine use during pregnancy among women attending outpatient clinics in Hail, Saudi Arabia $(\mathrm{N}=879)$

$\begin{array}{lc}\text { Risk } & \mathbf{n}(\%) * \\ \text { Birth defects } & 106(12) \\ \text { Miscarriage } & 360(41) \\ \text { Premature labour } & 290(33) \\ \text { Stillbirth } & 44(5) \\ \text { Long-term maternal health effects } & 79(9) \\ \text { "Percentages do not add up to 100\% as respondents were permitted to } \\ \text { select more than one risk. }\end{array}$

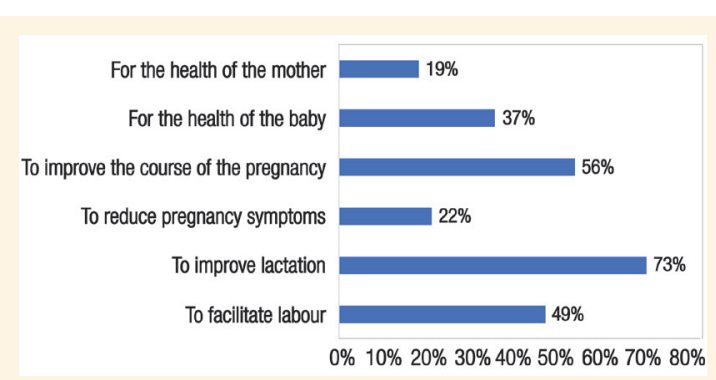

Figure 3: Reasons for herbal medicine use during pregnancy among women attending outpatient clinics in Hail, Saudi Arabia $(\mathrm{n}=294)^{*}$.

"Respondents were permitted to select more than one reason for use.

groups such as children, the elderly, pregnant women and developing fetuses. ${ }^{10,18}$ This is particularly worrisome as there is also a high rate of non-compliance with regulations that control the dispensing of prescriptiononly medications in community pharmacies in Saudi Arabia. ${ }^{19}$ Therefore, there is an urgent need to establish a national regulating body to monitor the use of herbal medicine to avoid adverse herb-drug interactions.

To the best of the authors' knowledge, the current study represents the first in the Hail region to determine the prevalence of and associated factors influencing herbal medicine use during pregnancy. The results indicated a high percentage of herbal medicine use, both prior to and during pregnancy (81\% and 33\%, respectively). Al-Ghamdi et al. similarly reported that $25.3 \%$ of pregnant women from the central region of Saudi Arabia used herbal products during pregnancy. ${ }^{20}$ In the current study, pregnant participants reported taking herbal medicines during all three stages of pregnancy, in the first (20\%), second (45\%) and third (35\%) trimesters. However, a significantly greater proportion of the respondents (85\%) reported using herbal medicines during the lactation period. Other researchers have reported similar results in other parts of Saudi Arabia and in nearby countries such as Palestine. ${ }^{20-23}$

In the present study, women with a high school diploma or higher (i.e. those with at least 12 years of formal education) and women who were working full-time were significantly more likely to use herbal

Table 3: Associations between herbal medicine use during pregnancy and demographic variables among women attending outpatient clinics in Hail, Saudi Arabia $(\mathrm{N}=879)$

$\begin{array}{lcc}\text { Variable } & \boldsymbol{\beta}(\mathbf{9 5 \%} \mathbf{C I}) & \boldsymbol{P} \text { value } \\ \text { Age } & 0.566(0.506-0.491) & 0.151 \\ \text { Education level } & 0.361(0.230-0.344) & <0.001 * \\ \text { Place of residence } & 0.125(0.385-0.377) & 0.235 \\ \text { Employment status } & 0.271(0.485-0.592) & <0.001 * \\ \text { CI = confidecne interval. *Significant at } P<0.010 . & \end{array}$


medicines during pregnancy compared to their less educated and unemployed counterparts. This contradicts the widespread assumption that the most likely users of risky and untested products, such as herbal products, are uneducated housewives in rural areas. Nevertheless, this finding is consistent with those of a previous study investigating the prevalence of herbal medicine use and costs in Australia, which reported that educated women were more likely to use herbal medicine. ${ }^{\text {? }}$

With regards to their knowledge of the risks associated with herbal medicine use during pregnancy, the majority of respondents in the current study believed that excessive consumption, although not explicitly defined, during pregnancy can cause various health risks to both the mother and child, including birth defects, miscarriage, premature labour, stillbirth and negative long-term effects on the mother's health. Indeed, some of these risks have scientific basis; for example, the consumption of moderate amounts of fenugreek during pregnancy purportedly increases milk production, whereas large quantities can cause uterine contractions, miscarriage or premature labour. ${ }^{24}$ However, while the exact sources of the respondents' knowledge regarding the health risks of herbal products were not determined, such assertions are likely based on hearsay and local cultural beliefs and practices.

When asked about their reasons for using herbal medicines during pregnancy, the majority of women in the present study believed that herbal medicines would generally improve their pregnancy, facilitate labour and increase milk supply. Such reasoning is probably based on cultural beliefs and practices. ${ }^{20,25}$ Interestingly, the latter two reasons may in part explain the increase in herbal medicine use during the second trimester and lactation period.

The current study was subject to certain limitations. Although there are no significant differences in traditional practices between different areas of Saudi Arabia, the current study was only conducted in one region; as such, the findings cannot be deemed reflective of the entire Saudi population. This study did not evaluate specific forms or methods of herbal product use or the prevalence of side-effects following usage, as such variables were deemed beyond the scope of the study. Some of the participants were not pregnant at the time of the survey and were therefore reporting experiences and practices from their last pregnancy; in some cases, this may have occurred as much as a decade beforehand. This could have resulted in recall bias for some of the responses, particularly those assessing herbal medicine use during the lactation period. This may have had an impact on the generalisability of the results.

\section{Conclusion}

To the best of the authors' knowledge, this is the first study to investigate the prevalence of herbal medicine use among pregnant women in Hail, Saudi Arabia. The findings indicate a high prevalence of herbal medicine use during pregnancy in the region, most likely influenced by local cultural practices. Therefore, urgent measures are needed to raise public awareness regarding the risks of herbal medicine use without professional advice. In addition, healthcare providers should ensure that pregnant patients disclose information concerning herbal product use in order to avoid health complications and drug interactions during treatment.

\section{CONFLICT OF INTEREST}

The authors declare no conflicts of interest.

\section{FUNDING}

No funding was received for this study.

\section{References}

1. World Health Organization. Legal status of traditional medicine and complementary/alternative medicine: A worldwide review. From: www.who.int/iris/handle/10665/42452 Accessed: Jun 2019.

2. Aljofan M, Netter HJ, Aljarbou AN, Hadda TB, Orhan IE, Sener B, et al. Anti-hepatitis B activity of isoquinoline alkaloids of plant origin. Arch Virol 2014; 159:1119-28. https://doi.org/10. 1007/s00705-013-1937-7.

3. Bent S. Herbal medicine in the United States: Review of efficacy, safety, and regulation - Grand rounds at University of California, San Francisco Medical Center. J Gen Intern Med 2008; 23:854-9. https://doi.org/10.1007/s11606-008-0632-y.

4. World Health Organization. WHOtraditional medicine strategy: 2002-2005. From: www.wpro.who.int/health_technology/boo k_who_traditional_medicine_strategy_2002_2005.pdf Accessed: Jun 2019.

5. Eisenberg DM, Kessler RC, Foster C, Norlock FE, Calkins DR, Delbanco TL. Unconventional medicine in the United States: Prevalence, costs, and patterns of use. N Engl J Med 1993; 328:246-52. https://doi.org/10.1056/nejm199301283280406.

6. Nissen N. Practitioners of Western herbal medicine and their practice in the UK: Beginning to sketch the profession. Complement Ther Clin Pract 2010; 16:181-6. https://doi.org/10.1016/j. ctcp.2010.06.001.

7. MacLennan AH, Wilson DH, Taylor AW. Prevalence and cost of alternative medicine in Australia. Lancet 1996; 347:569-73. https://doi.org/10.1016/S0140-6736(96)91271-4.

8. National Center for Complementary and Integrative Health. The use of complementary and alternative medicine in the United States. From: https://nccih.nih.gov/research/statistics/2007/ca msurvey_fs1.htm Accessed: Jun 2019.

9. Barnes PM, Powell-Griner E, McFann K, Nahin RL. Complementary and alternative medicine use among adults: United States, 2002. Adv Data 2004; 343:1-19. https://doi.org/10.1016/ j.sigm.2004.07.003

10. Ekor M. The growing use of herbal medicines: Issues relating to adverse reactions and challenges in monitoring safety. Front Pharmacol 2014; 4:177. https://doi.org/10.3389/fphar.2013.00177. 
11. Holden SC, Gardiner P, Birdee G, Davis RB, Yeh GY. Complementary and alternative medicine use among women during pregnancy and childbearing years. Birth 2015; 42:261-9. https://doi.org/10.1111/birt.12177.

12. Kim Sooi L, Lean Keng S. Herbal medicines: Malaysian women's knowledge and practice. Evid Based Complement Alternat Med 2013; 2013:438139. https://doi.org/10.1155/2013/438139.

13. Broussard CS, Louik C, Honein MA, Mitchell AA; National Birth Defects Prevention Study. Herbal use before and during pregnancy. Am J Obstet Gynecol 2010; 202:443.e1-6. https://doi.org/10.1016/j.ajog.2009.10.865.

14. Kennedy DA, Lupattelli A, Koren G, Nordeng H. Herbal medicine use in pregnancy: Results of a multinational study. BMC Complement Altern Med 2013; 13:355. https://doi.org/10.1186/14726882-13-355.

15. Alkhamaiseh SI, Aljofan M. Prevalence of use and reported side effects of herbal medicine among adults in Saudi Arabia. Complement Ther Med 2020; 48:102255. https://doi.org/10.10 16/j.ctim.2019.102255.

16. Calapai G. European legislation on herbal medicines: A look into the future. Drug Saf 2008; 31:428-31. https://doi.org/10.21 65/00002018-200831050-00009.

17. Briggs DR. The regulation of herbal medicines in Australia. Toxicology 2002; 181-2:565-70. https://doi.org/10.1016/s0300483x(02)00483-3.

18. Paule S, Aljofan M, Simon C, Rombauts LJ, Nie G. Cleavage of endometrial $\alpha$-integrins into their functional forms is mediated by proprotein convertase 5/6. Hum Reprod 2012; 27:2766-74. https://doi.org/10.1093/humrep/des203.
19. Alshammari TM, Alhindi SA, Alrashdi AM, Benmerzouga I, Aljofan M. Pharmacy malpractice: The rate and prevalence of dispensing high-risk prescription-only medications at community pharmacies in Saudi Arabia. Saudi Pharm J 2017; 25:709-14. https://doi.org/10.1016/j.jsps.2016.10.001.

20. Al-Ghamdi S, Aldossari K, Al-Zahrani J, Al-Shaalan F, Al-Sharif S, $\mathrm{Al}-\mathrm{Khurayji} \mathrm{H}$, et al. Prevalence, knowledge and attitudes toward herbal medication use by Saudi women in the central region during pregnancy, during labor and after delivery. BMC Complement Altern Med 2017; 17:196. https://doi.org/10.1186/s12906-0171714-3.

21. Elolemy AT, Albedah AM. Public knowledge, attitude and practice of complementary and alternative medicine in Riyadh region, Saudi Arabia. Oman Med J 2012; 27:20-6. https://doi. org/10.5001/omj.2012.04.

22. Shraim NY, Shawahna R, Sorady MA, Aiesh BM, Alashqar GS, Jitan RI, et al. Community pharmacists' knowledge, practices and beliefs about complementary and alternative medicine in Palestine: A cross-sectional study. BMC Complement Altern Med 2017; 17:429. https://doi.org/10.1186/s12906-017-1940-8.

23. Suleiman AK. Attitudes and beliefs of consumers of herbal medicines in Riyadh, Saudi Arabia. J Community Med Health Educ 2014; 4:269. https://doi.org/10.4172/2161-0711.1000269.

24. Laelago T. Herbal medicine use during pregnancy: Benefits and untoward effects. In: Builders P, Ed. Herbal Medicine. Rijeka, Croatia: IntechOpen, 2018. https://doi.org/10.5772/intechopen. 76896.

25. Rassool GH. Cultural competence in nursing Muslim patients. Nurs Times 2015; 111:12-15. https://doi.org/10.1007/978-1137-35841-7. 